\title{
Research on PDC bit Drilling Rate Equation in Daqing Medium-Deep Well Based on Rock Breaking Experiments by PDC Bit
}

\author{
Li Wei, Yan Tie, Xu Xinghua* and Li Siqi \\ Northeast Petroleum University, Petroleum Engineering, Daqing Heilongjiang, 163318, China
}

\begin{abstract}
PDC bit drilling rate equation is one measuring criterion of PDC bit work efficiency. The reasonable PDC bit drilling rate equation could predict the penetration rate and provide guidance for field operation. This paper studied the influences of the parameters on PDC bit drilling rate, such as rock drillability, cutting teeth diameter, specific weight on bit and rotate speed, and regressed the relation equations between the above parameters and drilling rate for cement rock, white sandstone, yellow sandstone, red sandstone and granite based on the laboratory rock breaking experiments. The results showed that the regression equation between specific weight on bit and drilling rate is quadratic polynomial for the soft and intermediate hardness rock, such as cement rock, yellow sandstone and white sandstone. The regression equation is quartic polynomial, the regression equation between rotate speed and drilling rate is quadratic polynomial for the intermediate hardness rock, such as red sandstone. The field data verification results of Daqing Oilfield medium-deep well showed the fractional error in actual drilling speed and forecast drilling speed between $3.03 \%$ and $9.23 \%$ and the average error is $6.397 \%$. This explained that the modified PDC bit drilling rate equation could describe the drilling law preferably.
\end{abstract}

Keywords: Daqing Oilfield, drilling rate equation, medium-deep well, PDC bit, rock breaking experiments.

\section{INTRODUCTION}

PDC bit is a cutting type bit whose main rock breaking method is shear breaking, it could achieve drilling in medium-deep well formation [1,2]. The research and application of PDC bit drilling rate equation are one of the main tasks in drilling engineering, because the drilling efficiency influences drilling progress and cost directly $[3,4]$. The drilling rate of PDC bit is related to bit structural parameters, rock parameters, mechanical parameters, hydraulic parameters and drilling fluid properties parameters $[5,6]$. Building the reasonable PDC bit drilling rate equation could predict the penetration rate and provide guidance for field engineers in guiding drilling operation [7-9].

Nowadays, the common drilling rate models are Bingham equation, Young's equation and Eminem equation and so on in drilling engineering. These drilling equations are built by analyzing mechanical parameters and hydraulic parameters on the basic of formation drillability parameters, but they ignored the characteristics of PDC bit rock breaking mechanism [10-13]. Based on the laboratory rock breaking experiments, this paper studied the influences of the parameters on PDC bit drilling rate and built the PDC drilling rate equation of Daqing Oilfield medium-deep well by considering the pressure environment of subsurface formation in Daqing Oilfield.

\section{THE PDC BIT ROCK BREAKING EXPERI- MENTAL EQUIPMENT AND PARMETERS}

When bits are breaking rock, the roller bits mainly produce the axial impact vibration, but PDC bits mainly produce

*Address correspondence to this author at the Daqing high-tech industrial development zone No.199, Daqing City, Heilongjiang Province, 163318, China; Tel: 0459-6503643; E-mail: xuxinghua19900528@163.com the circumferential torsional impact vibration. So it is very common that PDC bits produce stick-slip phenomenon in real drilling operation. Meanwhile, the main tool of drilling deep formation is PDC bits, and how to improve the rock breaking efficiency of deep wells and reduce the failure of drill wear are also the focus of current researches.

The experimental equipment is shown as Fig. (1). The diameters of experimental PDC bit are $\Phi 50$ and $\Phi 75$, as shown in Fig. (2) and Fig. (3). The diameters of cutting teeth are $13.5 \mathrm{~mm}, 16.0 \mathrm{~mm}$ and $19.0 \mathrm{~mm}$, their caster angles are all $15^{\circ}$. The samples are cement rock, white sandstone, yellow sandstone, red sandstone and granite, sum to 12 pieces.

The experimental parameters of PDC bit rock breaking experiment are shown in Table $\mathbf{1}$.

The rock breaking processes of five kinds of rock samples are shown in Fig. (4).

\section{THE PDC BIT ROCK BREAKING EXPERI- MENTAL RESULTS AND ANALYSIS}

\subsection{The Influence Analysis of Rock Drillability on Drilling Rate}

The rock drillability is an important indicator which describes the degree of difficulty of rock breaking. Applying micro-drilling method in testing drillability grade kd of five kinds of rock samples for evaluating the anti-drilling capability of rock samples, as shown in Table 2.

The PDC bit rock breaking experiments in different bit weights and rotate speeds with a sum of 5 groups 20 items were conducted. The changing trend figure between drilling rate and drillability grade in different rotate speeds was drawn by the example that bit weight is $15 \mathrm{kN}$ and PDC bit diameter is $75 \mathrm{~mm}$, as shown in Fig. (5). 


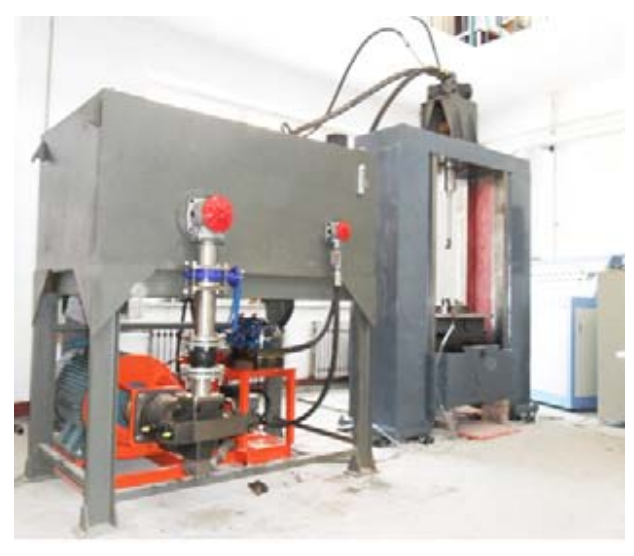

Fig. (1). The experimental equipment.

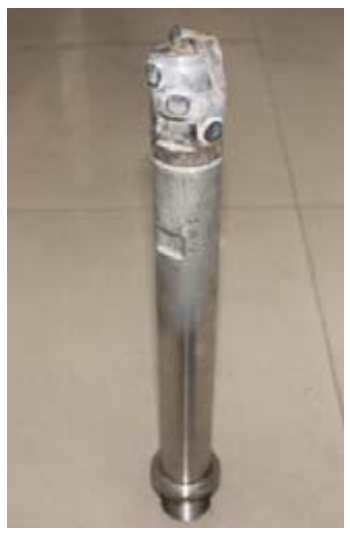

Fig. (2). $\Phi 50 \mathrm{~mm}$ Bit.

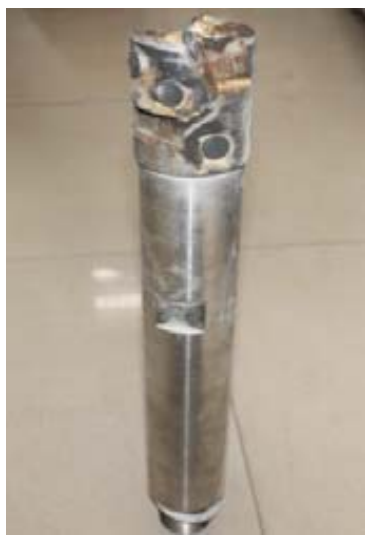

Fig. (3). $\Phi 75 \mathrm{~mm}$ Bit.

Table 1. The experimental parameters.

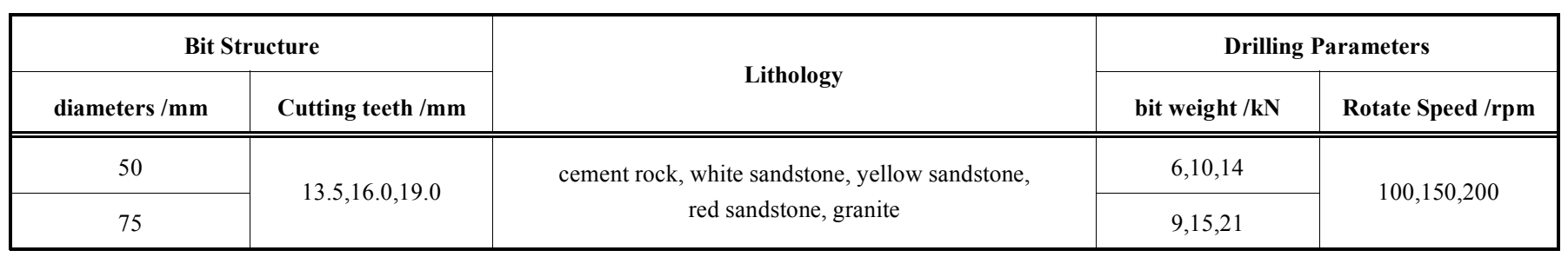
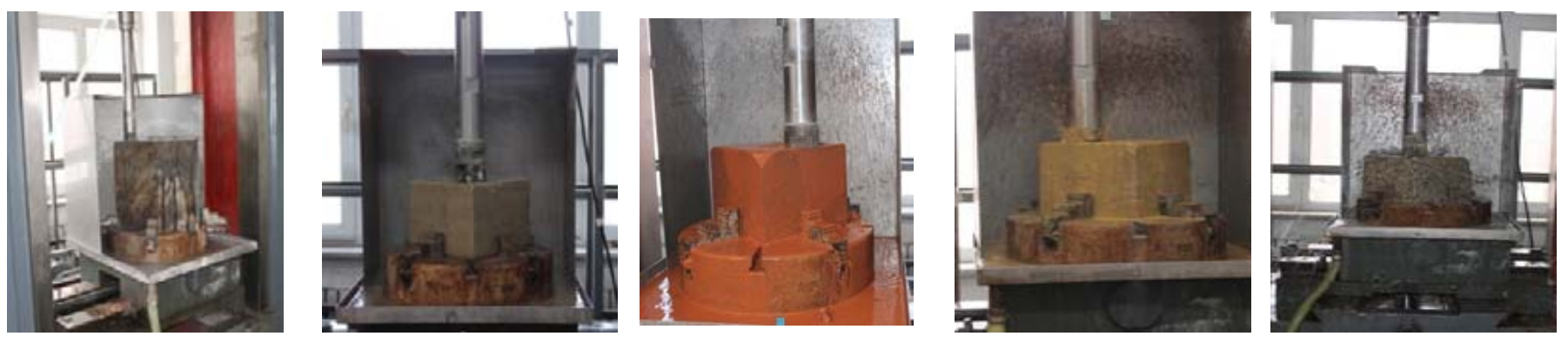

Fig. (4). The rock breaking experiments of PDC bit.

Table 2. The rock drillability grade.

\begin{tabular}{|c|c|c|c|c|c|c|}
\hline Rock Samples & \multicolumn{4}{|c|}{ Actual Drilling time /s } & Drillability Grade & Hardness Properties \\
\hline white sandstone & 32.26 & 30.67 & 31.72 & 31.88 & 4.79 & intermediate \\
\hline yellow sandstone & 7.97 & 8.42 & 8.45 & 8.28 & 3.05 & soft \\
\hline granite & 171.54 & 182.72 & 175.74 & 180.00 & 7.49 & hard \\
\hline
\end{tabular}

According to Fig. (5), the drilling rate decreases with the increase of drillability grade exponentially in different rotate speeds. And the higher rotate speed is the higher drilling rate of PDC bit.

\subsection{The Influence Analysis of Cutting Teeth Diameter on Drilling Rate}

The cutting tooth is an important structure parameter which influences rock breaking efficiency. The PDC bit rock 


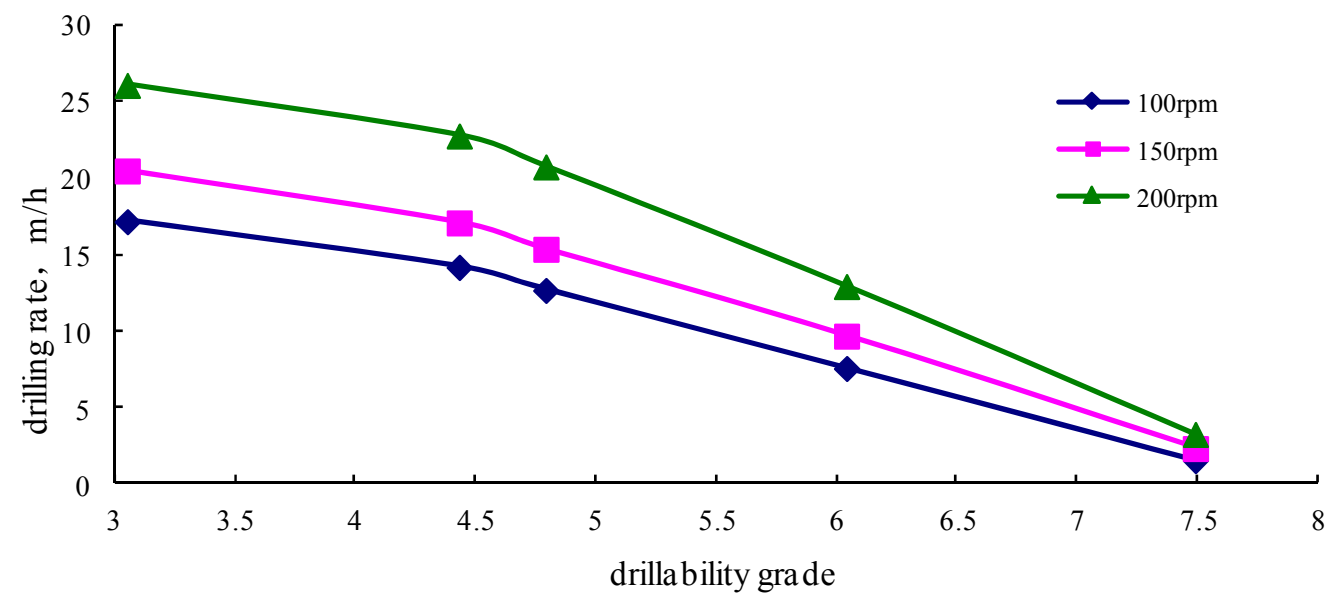

Fig. (5). The relation curve between drilling rate and drillability grade.

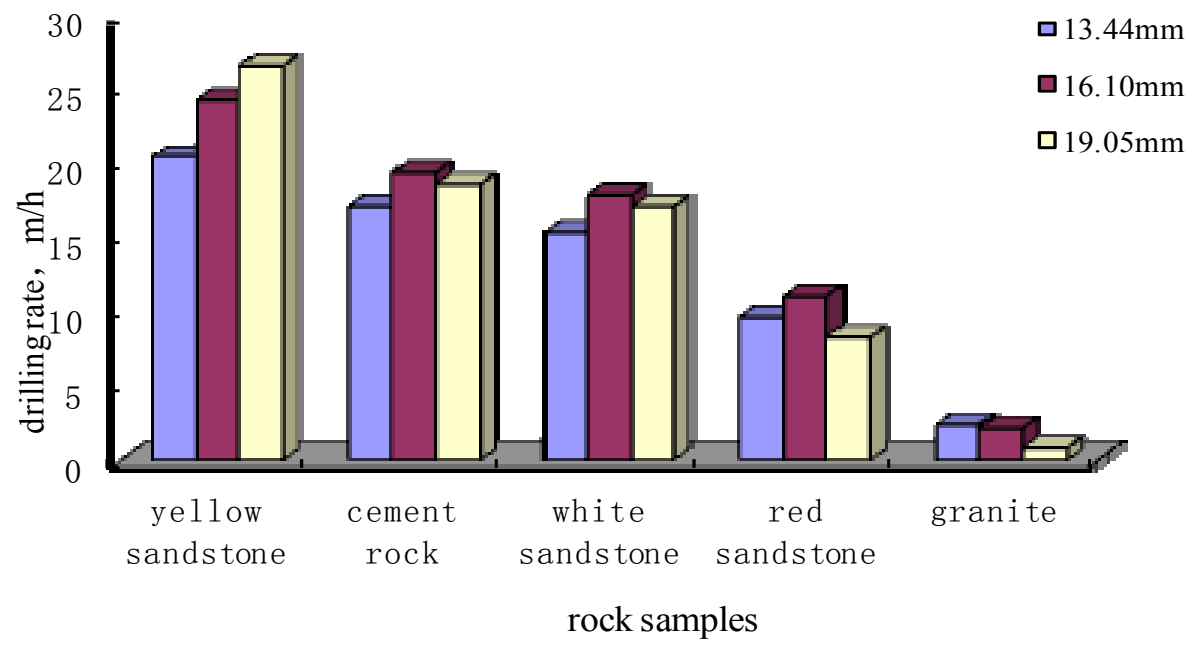

Fig. (6). The histogram between cutting teeth diameter and drilling rate.

breaking laboratory experiments whose caster angles are $15^{\circ}$ and cutting teeth diameters are $13.5 \mathrm{~mm}, 16.0 \mathrm{~mm}$ and $19.0 \mathrm{~mm}$ with a sum of 5 groups and 20 items were conducted. The relation curve between cutting teeth diameter and drilling rate was drawn by the drilling rate data in the condition of bit weight is $15 \mathrm{kN}$ and rotate speed is $150 \mathrm{rpm}$, as shown in Fig. (6).

According to Fig. (6), the drilling rates of different cutting teeth diameters are different in same bit weight, rotate speed and rock sample. This explained that cutting teeth diameters had high influences on PDC bit drilling rate. For yellow sandstone whose drillability grade is lower, PDC bit drilling rate increases with the increase of cutting teeth diameters, for cement rock, white sandstone and red sandstone, PDC bit drilling rate increases firstly and then decreases with the increase in cutting teeth diameters, and for granite whose drillability grade is higher, $t$ drilling rate decreases with the increase of cutting teeth diameters rapidly.

\subsection{The Influence Analysis of Specific Weight on Bit on Drilling Rate}

The PDC bit rock breaking experiments in different specific weight on bit of different rock samples and rotate speeds with a sum of 5 groups and 20 items. The relation curve between specific weight on bit and PDC bit drilling rate was drawn by the example that cutting teeth diameter is $13.5 \mathrm{~mm}$ and PDC bit diameter is $75 \mathrm{~mm}$, as shown in Fig. (7) and Fig. (8).

The fitting regression analysis was done by experiment data, and it was made sure that the optimal regression equation was between specific weight on bit and drilling rate by example of white sandstone, as shown in Table 3.

The laboratory experiment results showed that the relationship between specific weight on bit and drilling rate is polynomial, its correlation coefficient is approximately 1 . These results are different from the research results whose relationship between specific weight on bit and drilling rate is considered power function. The regression equation is quadratic polynomial for the soft and intermediate hardness rock, such as cement rock, yellow sandstone and white sandstone, and it is quartic polynomial for the intermediate hardness rock, such as red sandstone, as shown in equation (1) and equation (2).

$$
\begin{aligned}
& V_{s}=\mathrm{a} W_{\mathrm{p}}^{2}+\mathrm{b} W_{\mathrm{p}}+\mathrm{c} \quad\left(0<K_{\mathrm{d}} \leq 6\right) \\
& V_{s}=\mathrm{a} W_{\mathrm{p}}^{4}+\mathrm{b} W_{\mathrm{p}}^{3}+\mathrm{c} W_{\mathrm{p}}^{2}+\mathrm{d} W_{\mathrm{p}}+\mathrm{e} \quad\left(K_{\mathrm{d}}>6\right)
\end{aligned}
$$

In the equation, $\mathrm{a}, \mathrm{b}, \mathrm{c}, \mathrm{d}$ and e are regression coefficients. 


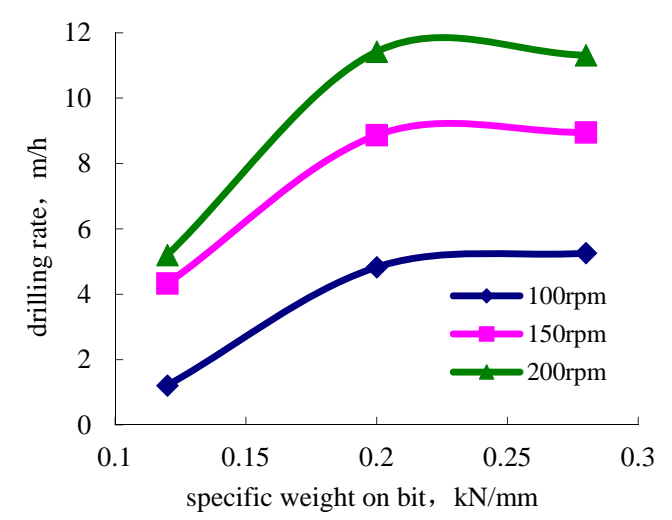

Fig. (7). The 50mm PDC bit in white sandstone.

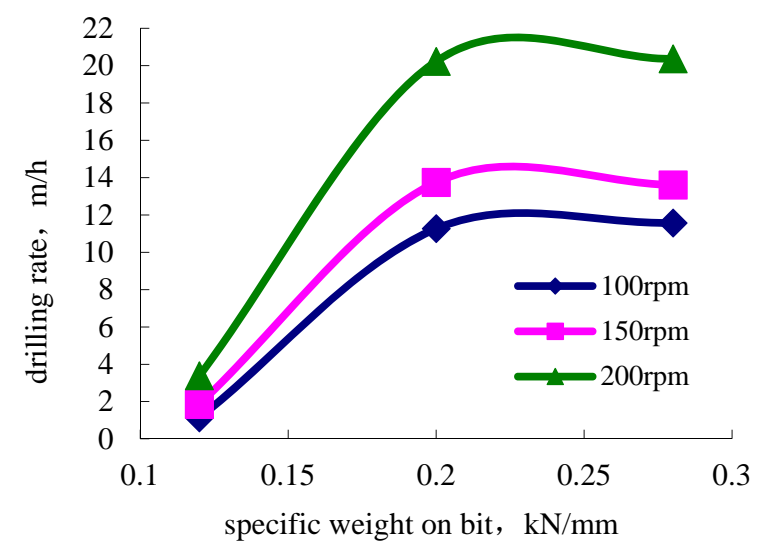

Fig. (8). The $75 \mathrm{~mm}$ PDC bit in white sandstone.

Table 3. The regression equation between specific weight on bit and drilling rate of white sandstone.

\begin{tabular}{|c|c|c|c|c|c|}
\hline Lithology & $\begin{array}{l}\text { Drillability } \\
\text { grade }\end{array}$ & $\begin{array}{l}\text { bit diameter } \\
\quad / \mathbf{m m}\end{array}$ & $\begin{array}{l}\text { Rotate Speed } \\
\text { /rpm }\end{array}$ & The Optimal Regression Equation & $\begin{array}{c}\text { Correlation Coefficient } \\
\qquad \mathbf{R}^{2}\end{array}$ \\
\hline \multirow{5}{*}{$\begin{array}{c}\text { white } \\
\text { sandstone }\end{array}$} & \multirow{5}{*}{4.79} & \multirow{3}{*}{50} & 100 & $R=-249.22 W_{\mathrm{P}}^{2}+125 W_{\mathrm{P}}-10.201$ & $\approx 1$ \\
\hline & & & 150 & $R=-348.44 W_{\mathrm{P}}^{2}+168.25 W_{\mathrm{P}}-0.843$ & $\approx 1$ \\
\hline & & & 200 & $R=-494.53 W_{\mathrm{P}}^{2}+236 W_{\mathrm{P}}-15.999$ & $\approx 1$ \\
\hline & & \multirow[t]{2}{*}{75} & 150 & $R=-939.84 W_{\mathrm{P}}^{2}+449.37 W_{\mathrm{P}}-8.531$ & $\approx 1$ \\
\hline & & & 200 & $R=-1306.3 W_{\mathrm{P}}^{2}+628.63 W_{\mathrm{P}}-3.245$ & $\approx 1$ \\
\hline
\end{tabular}

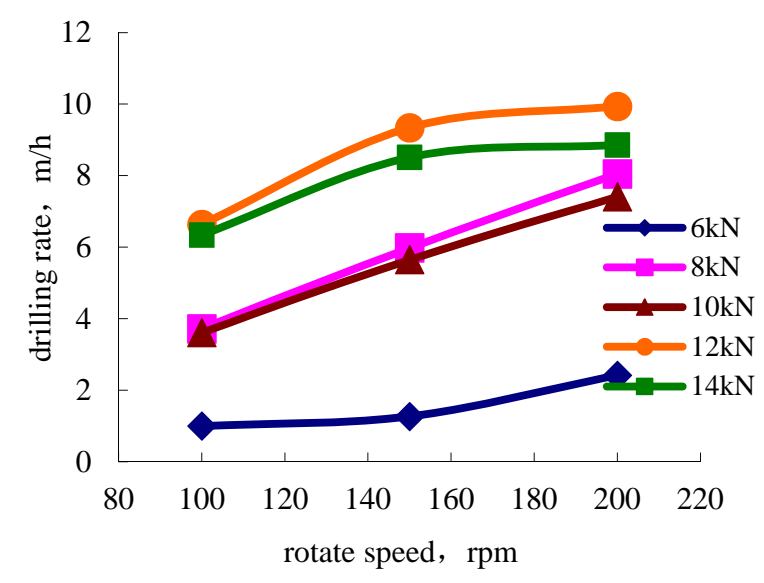

Fig. (9). The 50mm PDC bit in red sandstone.

\subsection{The Influence Analysis of Rotate Speed on Drilling Rate}

The PDC bit rock breaking experiments in different specific weight on bit of different rock samples with a sum of 5 groups and 20 items were conducted. The relation curve between rotate speed and drilling rate was drawn by the example that cutting teeth diameter is $13.5 \mathrm{~mm}$ and caster angle is $15^{\circ}$, as shown in Fig. (9) and Fig. (10).

The fitting regression analysis was done by experiment data, and it was made sure that the optimal regression equa-

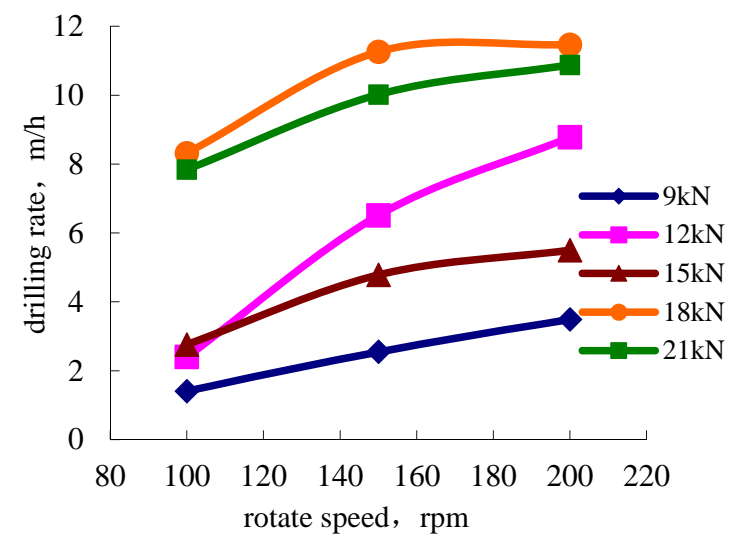

Fig. (10). The 75mm PDC bit in red sandstone.

tion was between rotate speed and drilling rate by example of red sandstone, as shown in Table 4.

The laboratory experiment results showed that the regression equation between rotate speed and drilling rate is quadratic polynomial, its correlation coefficient is above 0.9947 , as shown in equation(3).

$$
V_{s}=\mathrm{a} n^{2}+\mathrm{b} n+\mathrm{c} \quad\left(0<K_{\mathrm{d}} \leq 6\right)
$$

In the equation, $\mathrm{a}, \mathrm{b}$ and $\mathrm{c}$ are regression coefficients. 
Table 4. The regression equation between rotate speed and drilling rate of white sandstone.

\begin{tabular}{|c|c|c|c|c|c|}
\hline Lithology & $\begin{array}{l}\text { Drillability } \\
\text { Grade }\end{array}$ & $\begin{array}{l}\text { bit diameter } \\
/ \mathrm{mm}\end{array}$ & $\begin{array}{c}\text { Rotate Speed } \\
\text { /rpm }\end{array}$ & The Optimal Regression Equation & $\begin{array}{c}\text { Correlation Coefficient } \\
\mathbf{R}^{2}\end{array}$ \\
\hline \multirow{6}{*}{ Red Sandstone } & \multirow{6}{*}{6.04} & \multirow[b]{3}{*}{50} & 6 & $R=0.0002 n^{2}-0.0386 n+3.1$ & $\approx 1$ \\
\hline & & & 8 & $R=-4 \mathrm{E}-05 n^{2}+0.0547 n-1.37$ & $\approx 1$ \\
\hline & & & 10 & $R=-6 \mathrm{E}-05 n^{2}+0.0548 n-1.31$ & $\approx 1$ \\
\hline & & \multirow[b]{3}{*}{75} & 9 & $R=-4 \mathrm{E}-05 n^{2}+0.0328 n-1.47$ & $\approx 1$ \\
\hline & & & 12 & $R=-0.0004 n^{2}+0.1742 n-11.34$ & $\approx 1$ \\
\hline & & & 15 & $R=-0.0003 n^{2}+0.1054 n-5.18$ & $\approx 1$ \\
\hline
\end{tabular}

\section{THE FIELD EXAMPLES ANALYSIS OF PDC BIT DRILLING RATE EQUATION IN DAQING MEDIUM- DEEP WELL}

The drilling rate equation is theoretical method of calculating and predicting rock breaking efficiency in different formations, and is foundation of drilling parameter optimization. On the base of laboratory experiments and field drilling data of Liaohe Oilfield and Hebei Oilfield, Petroleum Exploration and Development Research Institute regressed the quartic drilling rate equation, as shown in equation (4).

$R=K W_{\mathrm{p}}^{\alpha} n^{\lambda} N_{c}^{f} e^{-\beta \Delta P}$

In the equation, $R$ is drilling rate; $K$ is colligation coefficient which is relating to lithology; $W_{\mathrm{p}}$ is bit pressure; $\alpha$ is bit pressure coefficient; $n$ is rotate speed; $\lambda$ is rotate speed coefficient; $N_{\mathrm{c}}$ is bit specific hydraulic horsepower; $f$ is formation hydraulic index; $\beta$ is colligation coefficient which is related to buried depth and compaction degree of formation; $\Delta P$ is bottom hole pressure difference.

According to the above rock breaking experiments, the quartic drilling rate equation was amended, as shown in following equation.

$R=\left\{\begin{array}{l}K_{h}\left(a_{1} W_{\mathrm{p}}^{2}+b_{1} W_{\mathrm{p}}+m_{1}\right)\left(a_{2} n^{2}+b_{2} n+m_{2}\right) N_{c}^{f} e^{-\beta \Delta P}\left(0<K_{\mathrm{d}} \leq 6\right) \\ K_{h}\left(a_{1} W_{\mathrm{p}}^{4}+b_{1} W_{\mathrm{p}}^{3}+c_{1} W_{\mathrm{p}}^{2}+d_{1} W_{\mathrm{p}}+m_{1}\right)\left(a_{2} n^{2}+b_{2} n+m_{2}\right) N_{c}^{f} e^{-\beta \Delta P}\left(K_{\mathrm{d}} \geq 6\right)\end{array}\right.$

In the equation, $K_{h}$ is colligation coefficient which is related to lithology.

The drilled formation of Daqing medium-deep well is mainly central depression area in Songliao basin. The formations, from shallow to deep in sequences, are MingShui Group, SiFangtai Group, NenJiang Group, YaoJia Group, QingShankou Group and QuanTou Group. It is necessary to build rock drillability grade profile map of central depression area for the application of model in Daqing Oilfield, as shown in Fig. (11).

When the data regression, the correlation coefficient $R^{2}$ is 0.752 , the optimal regression equation is:
$K_{\mathrm{d}}=141.0 H+952.6$

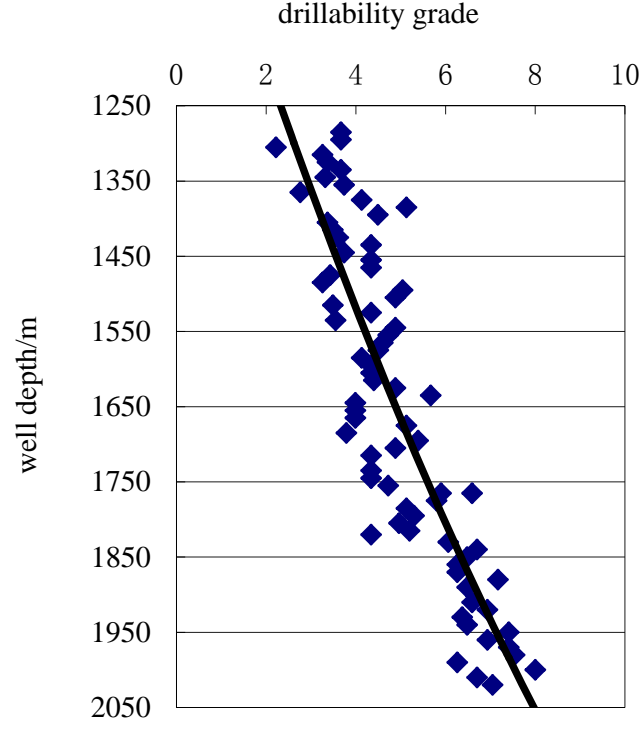

Fig. (11). The rock drillability grade profile map.

The optimal regression equation is based on the correction model data of quartic drilling rate equation. And PDC bit drilling rate equation of central depression area in Songliao basin was taken by multiple regression on the basic of field drilling data in Daqing Oilfield. The formations are shown in Table 5.

In order to verify the practicability and veracity of PDC bit drilling rate equation, the contrastive analysis was done of field drilling data of 10 horizons in 4wells, as shown in Table 6.

According to Table 6, the fractional error between actual drilling speed and forecast drilling speed is between $3.03 \%$ and $9.23 \%$, the average error is $6.397 \%$. The variation trend 
Table 5. The multiple regression fit coefficient.

\begin{tabular}{|c|c|c|c|c|c|c|c|c|c|c|c|}
\hline $\begin{array}{l}\text { Yaojia } \\
\text { Group }\end{array}$ & 3.32 & -9.81 & 1.11 & - & - & 0.59 & 0.57 & -184.75 & 16192.93 & -0.35 & -2.87 \\
\hline $\begin{array}{l}\text { Qing One- } \\
\text { two horizon }\end{array}$ & 43.53 & 60.22 & 17.98 & - & - & 5.40 & -2.97 & 821.18 & -55318.33 & 1.52 & 0.77 \\
\hline $\begin{array}{c}\text { Quan Four } \\
\text { horizon }\end{array}$ & 30.70 & 382.96 & -32.70 & -17.43 & -2.56 & 0.89 & -0.48 & 118.17 & -7033.83 & -0.25 & 1.24 \\
\hline
\end{tabular}

Table 6. The verified result of PDC bit drilling rate equation.

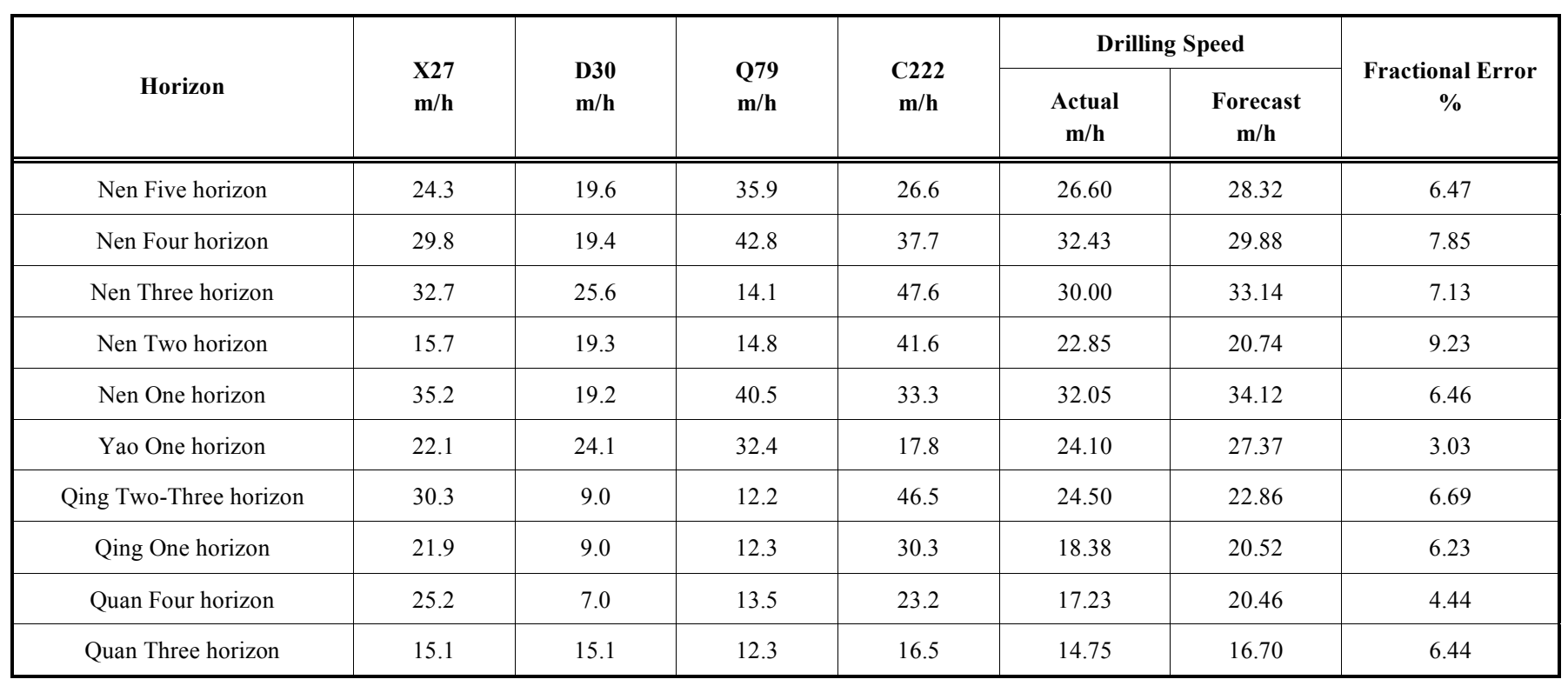

between actual drilling speed and forecast drilling speed is very close; this explained that the modified PDC bit drilling rate equation could describe the drilling law preferably.

\section{CONCLUSION}

1. Studied the influences of the parameters on PDC bit drilling rate, such as rock drillability, cutting teeth diameter, specific weight on bit and rotate speed, by "The simulative and analytic system of rock breaking". The drilling rate decreases with the increase in drillability grade exponentially in different rotate speeds, and increases with the increase of cutting teeth diameters for stone whose drillability grade is lower; and decreases with the increase of cutting teeth diameters rapidly for stone whose drillability grade is higher. And the relationship between specific weight on bit or rotate speed and drilling rate is polynomial and quadratic polynomial independently.

2. The laboratory experiment results, specific weight on bit and drilling rate, showed that the regression equation is quadratic polynomial for the soft and intermediate hardness rock $\left(K_{\mathrm{d}}<6\right)$, such as cement rock, yellow sandstone and white sandstone, and it is quartic polynomial for the intermediate hardness rock $\left(K_{\mathrm{d}}>6\right)$, such as red sandstone.

3 . The laboratory experiment results rotate speed and drilling rate, showed that the regression equation is quadratic polynomial.

4. Regressed the quartic drilling rate equation by experimental analysis results. The field data verification results of Daqing Oilfield medium-deep well showed that the fractional error in actual drilling speed and forecast drilling speed is between $3.03 \%$ and $9.23 \%$ and the average error is $6.397 \%$. This explained that the modified PDC bit drilling rate equation could describe the drilling law preferably.

\section{CONFLICT OF INTEREST}

The authors confirm that this article content has no conflict of interest.

\section{ACKNOWLEDGEMENTS}

National Natural Science Foundation of China (Nos. 51274072) are gratefully acknowledged. 


\section{REFERENCES}

[1] T. P. Chen, and J.B. Hu, Petroleum Engineering. Beijing: Petroleum Industry Press, 2000.

[2] H. Hu, "Personalized PDC bit development status and application prospect", Science and Technology Information, vol. 9, pp.140141, March 2012.

[3] Y. H. Lin, Y. Y. Zong, and Z. Liang, "The developments of ROP prediction for oil drilling", Petroleum Drilling Techniques, vol. 32, pp.10-12, January 2004.

[4] Y. X. Wang, S. H. Zhang, and H. H. Li, "Effective approach to improving drilling rate according to the analysis on drilling rate equation", Exploration Engineering Media, vol.37, pp.14-17, March 2010

[5] Y. Han, Modeling and Appling of Drilling Speed of Cutting Type PDC Bit. Da Qing: Northeast Petroleum University Press, 2012.

[6] H. T. Zhou, and Y. H. Zhou, "Differential pressure effecting PDC bit on penetration rate", Oil Drilling and Production Technology, vol.18, pp.31-34, January 1996

[7] J. Y. Du, Research on Penetration Rate Equation of Roller Bit Based on the Theory of Invasion. Da Qing: Northeast Petroleum University Press, 2012.
[8] B. Mahmood, and A. Rahman, "Investigation of various ROP models and optimization of drilling parameters for PDC and roller-cone bits in shadegan oil field", Journal of Petroleum Technology, vol.18, pp. 1-4, January 2010.

[9] M. S. Wang, Z. K. Li, and Y. C. Geng, "Laboratory study on rock breaking mechanism and its application", Rock and Soil Mechanics, vol. 29, pp. 711-715, March 2008 .

[10] Y. G. Liu, and H. Y. Wang, "Initial research on rock-breaking mechanism for gas drilling in Xushen gas field", Acta Petrolei Sinica, vol.29, pp. 773-776, September 2008.

[11] T. Yan, and S. B. Li, Rock Mechanics Theory and the Practice of Deep Hole. Beijing: Petroleum Industry Press, 2002.

[12] T. Yan, W. Li, and X. L. Bi, "Fractal analysis of energy consumption of rock fragmentation in rotary drilling", Chinese Journal of Rock Mechanics and Engineering, vol.27, pp. 3649-3654, September 2008 .

[13] H. Zhang, and D. L. Gao, "A new method for predicting drillability of un-drilled formation", Acta Petrolei Sinica, vol.27, pp. 97-100, January 2006.

Received: July 30, 2014

Revised: November 12, 2014

Accepted: November 14, 2014

(C) Wei et al.; Licensee Bentham Open.

This is an open access article licensed under the terms of the Creative Commons Attribution Non-Commercial License (http://creativecommons.org/licenses/by-nc/3.0/) which permits unrestricted, non-commercial use, distribution and reproduction in any medium, provided the work is properly cited. 